pushing on the catheter from the nasal end. In an average adult the catheter should be passed for 1 a distance of about $30 \mathrm{~cm}$ from the ol of the noge on about $5 \mathrm{~cm}$ further than the cistan

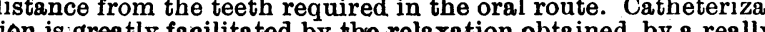
ion is greatly facilitated by the relaxation obtained by a really deep anaesthesia and by the use of a large size laryngoscope. 4. Six pieces of ordinary rubber tubing (sizes 22, 24, 26, 28 and 32 French catheter gauge, walls $2 \mathrm{~mm}$. thiek) are smeare with sterile vasoline, and, starting with the smallest, rapidly passed one after the other through the oppasite naris. This manœuvre gradually dilates the nasal passage, and enables a tube large enough to provide a sufficient return airway in most cases to be used. The length of tubing to pass may be roughly ostimated by the distance between the patient's ala and the external auditory meatus of the same side; but the most suit bole length can really only be found by trial in each case, 8 good return aifway with the end of the tube as near the glottis as possible being the aim. A metal ungle piece may be fitted into the outer end of the tube to direct the ansesthetic vapan oway from the surgeon, and prevent towels obstructing the irwer. The bek of the mouth is now packed with o long strip of gauze.

Fig. 2 illustrates the method in use during a plastic operation on the lips. A sufficient nasal return airway

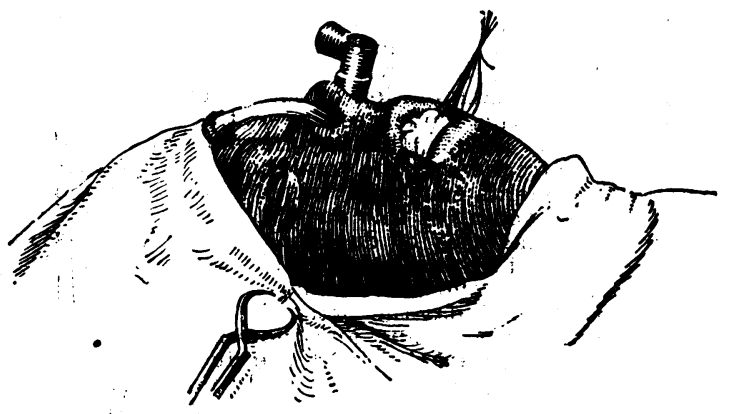

Fra. 2.

cannot always be obtained in this manner, but occasionally it may be impraved by increasing or decreasing the degree of extension of the neck. Again, it is sometimes found that if a tube:which has remained in for a short time and dilated the nasal passage be removed, the larger airway obtained by its removal proves sufficient.

Occasionally, when the catlueter is passed through the nose with a wire in it, as described above, and pushed on, the cough characteristic of its passage into the trachea occurs, and, on inspection, the fact that it has actually passed between the cords is confirmed. Working on this, attempts were made to judge the curve on the catheter required to direct its end towards the mid-point of the thyroid cartilage after passage through the nose; but so far experiments have shown this to be a very uncertain method of tracheal catheterization, the correct curve for each case being very difficult to estimate. The guiding rod, nasal tubes, and metal angle piece were made for me by Messrs. Mayer and Phelps.

\section{A CASE OF CEREBELLAR TUMOUR.}

R. T. WHLLIAMSON, M.D., F.R.C.P.,

CONSULTING PHYGTOIAN TO THE ROYAL INFIRMARY, MANCHESTER.

WITH respect to the ataxia in localized cerebellar tumour, different statements have been made in British and foreign medical literature as regards, the side to which the patient tends to fall when attempting to walk. By some distinguished British and Continental physicians it is stated that, in the ataxia of cerebellar tumour, when the patient walks there is no constant relation between the side to which he tends to fall and the side of the tumour. By others it is stated that the patient tends to fall to the side of the lesion. According to some physicians, when the posterior part of the middle lobe of the cerebellum is affected the patient tends to fall backwards when walking; and when the anterior part is affected the patient tends to fall forwards.

The abstract of the notes of the followingcase may be of interest, because it tends to support the view. which has ben expressed by certain English physicians with respect to the direction in which the patient tends to fall. The case is an instance. also. of the deviation and rotation of the head described by Dr. Grainger Stewart and Dr Gordon Holmes "as occurring in certain cases of cerebellar tumour."

M. G., a man aged 45, was sent to me by Dr. Sawers Scott. When first seen his chief symptom was headache. The optic discs were then normal, and no symptoms of cerebellar disease or other localized organic brain disease could be detected. I did not see the patient again for many months. When I next examined him definite symptoms of cerebellar, tumour had developed. He com plained of severe headache, and on examination the following were the chief symptoms: Double optic neuritis; internal strabismus of the left eye; paralysis of the left external rectus muscle; diplopia; ataxic gait; definite tendency to fall backwards and to the left when walkingthe last symptom, at the end of the illness, was very well marked; also when standing or sitting the head was tilted or rotated, so that the chin was directed, or approximated, to the right shoulder.

The autopsy revealed a cerebellar tumour. It was situated at the posterior part of the cerebellum, just under the tentorium.

It affected the

posterior balf of the middle lobe (or vermis) and extended to the left lobe, affecting almost the whole of the posterior half of this lobe, but it only affected a very small por. tion of the right lobe, quite close to the middle lobe. The

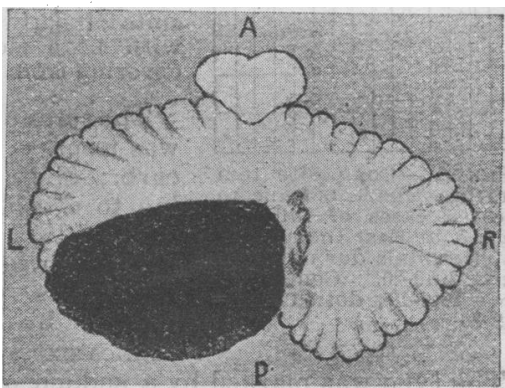

Horizontal section through middle of cere bellum. Position of tumour shaded. growth extended both to the upper and lower surfaces of the posterior half of the left lobe of the cerebellum, but it was most extensive in the central or middle portion of this lobe. The dentate nucleus was seen outside the growth on the right side. The growth occupied the position of this nucleus on the left side and the position of the roof nuclei in the middle lobe. The growth was a plexiform angio-sarcoma, the cells being chiefly spindle cells.

\section{A NOTE ON INFLUENZA IN INDIA, 1918-20.} BY

\section{H. G. WATERS, M.R.C.S., L.R.C.P., D.P.H.CAMB.} D.T.M.AND H.

CHIEF MEDICAL OFFICER, EAST INDIAN RAILWAY.

Mx report on influenza, published in February, 1919, gives an account of the result of treating the 1918 influenza out break by stimulants instead of by the usual depressant mixtures containing salicylates. It records the treatment of 28,859 cases, with 509 deaths-a case-mortality of 1.7 per cent.

The second outbreak in 1920 gave a general impression to all my staff of medical men, numbering almost 100 , that one attack of influenza protects the individual against a second attack. The following definite records, although of small numbers, are so confirmatory of this impression that we may, I think, accept them as proving that "one attack of influenza protects against a second," as much as measles does. The cases recorded were all clear to type, and not catarrhal cases, so often miscalled influenza.

At the three Oak Grove Schools, Mussoorie, we have a population of:

$\begin{array}{lllllr}\text { Boys' school } & \ldots & \ldots & \ldots & \ldots & 220 \\ \text { Girls' school } & \ldots & \ldots & . \ldots & \ldots & 118 \\ \text { Junior boys } & \ldots & \ldots & \ldots & \ldots . & 105 \\ \text { Junior girls } & \ldots & \ldots & \ldots & \ldots . & 72 \\ \text { Staff (includes families) } & \ldots & \ldots & \ldots & 56 \\ \text { Clerks ," } & , & \ldots & \ldots & \ldots & 9 \\ \text { Menials ", } & , & \ldots & \ldots & \ldots & 225 \\ \end{array}$

To attend on these we had one medical officer, two sub-assistant surgeons, and eight nurses. The records and attendance were therefore probably much better than those furnished in the average case. Every one of the nurses in turn contracted the 